\title{
O DISCURSO SOBRE A CONSCIÊNCIA EM MEMORIAIS DE EDUCADORES AMBIENTAIS
}

\section{The speech on the conscience in memorials of environmental educators}

\author{
Cláudia Lino Piccinini ${ }^{1}$
}

\begin{abstract}
Resumo: Tendo como ponto de partida pesquisa que analisou os caminhos de formação e de atuação profissional de um grupo de educadores ambientais, chamaram a atenção aspectos da narrativa que denominei de "discurso sobre a consciência". Trabalhando com base em memoriais autobiográficos destes educadores, e tendo como aporte teórico-metodológico a teoria da enunciação de Bakhtin (1986 e 2003), verificou-se que a visão manifesta não surgiu como consciência de classe, mas, em sua maioria, como consciência ingênua, mesclada ao desejo de poder contribuir para as mudanças das contradições socioambientais do capitalismo, sem assumir um papel de confronto à ideologia dominante.
\end{abstract}

Palavras-chave: Formação de professores. Educação ambiental. Autobiografia.

\begin{abstract}
Taking as a starting point research that examined the training paths and professional performance of a group of environmental educators, narrative aspects I have denominated 'the discourse of conscience' called our attention. Working from the autobiographical memorials of these educators, and with the theoretical and methodological theory of enunciation of Bakhtin (1986 and 2003), it was clear that the view was not appear as class conscious, but mostly as naive consciousness, mixed with the desire to contribute to the changes of the social-environmental contradictions of capitalism, without assuming a role of confrontation to the dominant ideology.
\end{abstract}

Keywords: Teacher's professional performance. Environmental education. Autobiography.

\footnotetext{
${ }^{1}$ Licenciada em Ciências Biológicas, doutora em Educação. Docente, Departamento de Didática, Faculdade de Educação, Universidade Federal do Rio de Janeiro. Rio de Janeiro, RJ, Brasil. <clpiccinini@gmail.com>

UFRJ, Faculdade de Educação, Departamento de Didática - $2^{\circ}$ andar Avenida Pasteur, 250

Campus da Praia Vermelha - Rio de Janeiro, RJ

$22.290-240$

679

Ciência : Ẽ Educação, v. 17, n. 3, p. 679-692, 2011
} 


\section{Introdução}

Inicio com a apresentação dos caminhos metodológicos da pesquisa, indicando os processos de seleção dos textos autobiográficos analisados à luz da teoria da enunciação de Mikhail Bakhtin (1986; 2003). Do texto memorialístico, obtenho mais do que uma simples interpretação das narrativas dos acontecimentos e das ideias, mas a possibilidade de relacionar as diversas trajetórias e ir além dos "não-ditos" dos educadores ambientais.

Da interlocução com o material empírico, tendo como bases teóricas o materialismo histórico de Marx e Engels, e a perspectiva gramsciana subsidiando a visão do trabalho como trabalho intelectual, aproprio-me também de estudos do campo da Educação Ambiental (EA) para problematizar e debater "os discursos sobre a consciência" que surgem dos enunciados.

Em seguida, passo ao debate que pretende trazer elementos não para discutir o conceito de consciência, mas verificar como este surge nas narrativas de educadores ambientais e, por conseguinte, relacioná-lo às ideias que atravessam perspectivas ora idealistas e abstratas, ora críticas de compreensão da realidade e do trabalho de educar ambientalmente. Pretendo, também, verificar a existência do que Gramsci (2004) chamou de consciência coletiva, se esta aparece nas narrativas dos educadores ambientais, em que momento aparece e em que tipo de interlocução.

\section{Memórias e linguagem: o caminho metodológico}

Diante da diversidade de formas de interlocução "pesquisadora-pesquisados", optou-se pela escolha de memoriais como possibilidade de se acessar a trajetória formativa e profissional de educadores ambientais. Os memoriais, cristalizados sob a forma de uma ferramenta de análise autobiográfica, constituem um conjunto empírico elaborado e escrito pelos personagens centrais da análise.

O ato de organizar, por meio da escrita, a experiência vivida não é tarefa usual e simples. Muitos educadores consultados para participarem desta investigação não responderam às solicitações; outros informaram a impossibilidade de realizarem esta tarefa, que consideraram exaustiva e demorada, uma tarefa que lhes exigiria a imersão em seus cotidianos de vida, pois, nos memoriais, é preciso transformar memória em objeto de análise, de reflexão e, além disso, convertê-la em documento escrito.

A opção pela autobiografia na forma de texto escrito nos remete a diversas possibilidades, tais como: (i) relacionar história e memória; (ii) captar a atmosfera que envolve os sujeitos; (iii) captar o idealismo e escolhas das mais diversas ordens (imaginação, ética, aspiração); (iv) captar o diálogo do sujeito com seus interlocutores ao longo de uma sequência sóciohistórica, enfim, buscar compreender a totalidade de ações e relações a que estão submetidos os personagens que acompanhamos ao longo deste trabalho.

Os documentos utilizados possuem especificidades que precisam ser consideradas, pois estão voltados, sobretudo, para a descrição e detalhamento dos percursos de formação e atuação no campo profissional, sendo gerados com esta finalidade específica. Tais características, por um lado, circunscrevem o objeto de análise, por outro, aprofundam as questões que foram caras a este estudo. 
Para delimitar o grupo de educadores ambientais, partiu-se de um perfil inicial:

. a participação no desenvolvimento de trabalhos de educação ambiental;

- o exercício em algum tipo de atividade docente;

- a contribuição na produção de pesquisas no campo da EA;

- possuir um memorial pronto.

O perfil se justifica a partir da concepção de que um educador ambiental precisa estar incluído em um processo coletivo de reflexão sobre sua prática - daí o interesse por personagens que, em exercício docente, também estivessem de alguma forma preocupados com a produção de conhecimento e com a publicização destes conhecimentos a partir da pesquisa em EA.

Ao se selecionarem educadores participantes de encontros da área de EA (ou que incluíam a área) ${ }^{2}$, esperava-se encontrar profissionais que atendessem ao perfil acima e que, também, tivessem memoriais prontos, já elaborados, pois havia o conhecimento das dificuldades concretas de produção de tal documentação. Além do mais, não se intensionava uma produção "especial" para esta pesquisa, o que poderia se constituir como uma interferência significativa na redação dos registros.

Feita a seleção, o corpus da pesquisa totalizou 22 memoriais recebidos a partir de contato por meio eletrônico (e-mails). Destes, oito memoriais nos interessam particularmente para a análise aqui empreendida, visto que apontam discursos que permitem problematizar, estabelecer relações e compreender a formação e o trabalho de educadores ambientais.

$\mathrm{Na}$ etapa analítica, trabalho com a perspectiva dialética, tendo como aporte teórico os trabalhos de Mikhail Bakhtin (1986; 2003) e sua teoria da enunciação. Em tal perspectiva, o memorial não se constitui como um texto fechado em si mesmo, mas como uma narrativa que dialoga internamente e com a realidade ao seu redor. O material empírico encontra lugar para a reflexão, como se fosse um momento de aprofundamento à parte, mas que remete ao contexto das experiências vividas.

A escolha teórica possibilita mediarmos a análise a partir de um referencial fundamentado no materialismo dialético de linguagem, capaz de compreendê-la nos seus aspectos sócio-históricos ideológicos e como acontecimento dialógico (BAKHTIN, 1986).

"O pensamento das ciências humanas nasce como pensamento sobre pensamentos dos outros [...]. Independentemente de quais sejam os objetivos de uma pesquisa, só o texto pode ser o ponto de partida" (BAKHTIN, 2003, p. 308).

Credito tal perspectiva ao que Bakhtin chamou de "criação ideológica do grupo social e da época" (BAKHTIN, 1986, p.112), às disputas no seio da luta de classes, e não ao inconsciente ou a um sujeito abstrato com o qual a pesquisadora se comunica.

A palavra dirige-se a um interlocutor: ela é função da pessoa desse interlocutor; variará se se tratar de uma pessoa do mesmo grupo social

${ }^{2}$ Os encontros foram: o $5^{\circ}$ IBEROEA (2008), a 29 Reunião Anual da ANPED (2006), os Encontros Regionais de Ensino de Biologia - EREBIO (2001, 2003 e 2005) e os Encontros de Pesquisa em EA - EPEA (2005 e 2007). 
Piccinini, C. L.

ou não, se esta for inferior ou superior na hierarquia social, se estiver ligada ao locutor por laços sociais mais ou menos estreitos [...]. (BAKHTIN, 1986, p. 112)

Nesse sentido, "todo enunciado concreto é um elo na cadeia da comunicação discursiva de um determinado campo" (BAKHTIN, 2003, p. 296), também entendido, por Marx e Engels (2007), como um campo de disputas socioideológicas, políticas e, em primeira instância, de caráter econômico.

Tais referências permitem trabalhar o texto como fonte de dados e mais, trabalhar na tensão texto dos interlocutores (discurso dos memoriais) e texto da pesquisadora (com suas questões, seu discurso analítico e com sua própria visão de mundo) sem dicotomias, mas compreendendo as possibilidades de diálogo de dois textos, onde se destaca a diferença.

O texto só tem vida contatando com outro texto (contexto). Só no ponto deste contato de textos eclode a luz que ilumina retrospectiva e prospectivamente, iniciando dado texto no diálogo. Salientamos que esse contato é um contato dialógico entre textos (enunciados) e não um contato mecânico de 'oposição', só possível no âmbito de um texto (mas não dos textos e dos contextos) entre os elementos abstratos (os signos no interior do texto) e necessário apenas na primeira etapa da interpretação (da interpretação do significado e não do sentido). Por trás desse contato está o contato entre indivíduos e não entre coisas (no limite). (BAKHTIN, 2003, p. 401)

Esta abordagem também permite pensar sob a ótica da alteridade, isto é, "o quê e o como do que se diz supõem sempre o 'outro' em sua fundamental diversidade" (AMORIM, 2003, p. 11), o que representa uma importante problematização do ponto de vista epistemológico da relação estabelecida entre pesquisador e pesquisados.

O memorial é um registro das experiências vividas e que carrega consigo a autoridade de quem se remete à própria vida. São textos autobiográficos, onde a temporalidade e as marcas individuais estão presentes sob a forma de registro escrito das redes e conexões a que os indivíduos estão submetidos. Bakhtin se refere à escrita autobiográfica como a escrita do eu-para-si, como a "relação consigo mesmo" (BAKHTIN, 2003, p. 138), ou, ainda, como a "descrição de uma vida [...], auto-objetivação" (BAKHTIN, 2003, p. 139).

Partindo destas discussões, penso que os memoriais possuem uma autoridade como registro escrito. Portanto, considero os textos como dados primários, como a "única realidade imediata (realidade do pensamento e da vivência) [...]. Onde não há texto, não há objeto de pesquisa e de pensamento" (BAKHTIN, 2003, p. 307). O texto é "pensamento sobre pensamentos, do discurso sobre o discurso, do texto sobre os textos" (BAKHTIN, 2003, p. 307). 


\section{O discurso de construção da consciência}

Ao analisar os enunciados dos memoriais, verifico que oito educadores ambientais se referiram, em contextos diferenciados, aos termos "conscientização, conscientizar, tomada de consciência, consciência do inacabamento e construir a consciência".

As falas dos educadores ambientais indicam duas perspectivas: a quem se conscientiza - conscientização humana, conscientização da população - e sobre o que se conscientiza conscientização ambiental e conscientização ecológica. A respeito destes discursos sobre a construção da consciência, é necessário apontar que:

(i) São termos recorrentes tanto no campo da educação (FREIRE, 1981) quanto da educação ambiental (DIAS, 1993; DUTRA, 2005; JACOBI, 2003; BRASIL, 1997³);

(ii) De forma geral, está presente uma preocupação, por parte dos educadores ambientais, de que lhes cabe o papel de "transformador ou formador" da consciência alheia - do educando, da comunidade, da sociedade;

(iii) Existe uma predisposição para a utilização do termo como uma referência oriunda do senso comum;

(iv) "Não podemos empregar 'consciência' de maneira absoluta: toda consciência é consciência de alguma coisa, isto é, a necessidade, para a consciência, de existir como consciência de outra coisa distinta dela mesma, [...]" (JAPIASSU; MARCONDES, 1991, p. 56 - grifo da autora).

Nos memoriais, verifico que este discurso surge em momentos distintos da trajetória formativa e profissional. Dois memoriais o citam quando da descrição das lembranças préuniversitárias. A princípio, estão relacionados a uma visão de amor e interação com a natureza - "Aprendi a amar a natureza e a construir a consciência de que sou membro de uma das espécies que vivem sob a terra [...]" - ou no momento de traçar uma trajetória profissional motivada pela ideia de ecologia, de preservação e consciência ambiental - "A Ecologia oferecia então possibilidades de trabalho com preservação ecológica e conscientização ambiental de populacõos, [...]".

O discurso sobre a construção da consciência está também presente a partir da apresentação da formação (inicial e pós-graduação) dos educadores, em quatro memoriais (com seis enunciados). Dividem-se em ações desenvolvidas junto a comunidades através de experiências de extensão no período de estágio, e um caso como projeto escolar, na culminância de atividades pedagógicas junto aos responsáveis pelos alunos. Vejamos"

\footnotetext{
3 Analisando o PCN (1997) do tema transversal Meio Ambiente de $5^{\mathrm{a}}$ a $8^{\mathrm{a}}$ série, encontramos, em diversos contextos, as seguintes ocorrências: conscientizar (uma ocorrência na página 15), consciente (uma ocorrência na página 23), conscientização (duas ocorrências nas páginas 36 e 64), consciência (cinco ocorrências nas páginas 3, 8, 18, 39 e 42) e, por fim, tomada de consciência (uma ocorrência na página 39).

${ }^{4}$ As citações dos enunciados não sofreram qualquer tipo de adaptação ou correção ortográfica, sendo cópias dos memoriais. Para efeito de identificação, apresentamos os enunciados dos memoriais numerados, cada número indica um Educador Ambiental. Por questões éticas, evitamos, ao máximo, a identificação dos(as) interlocutores(as), caracterizando-os(as) apenas de forma abrangente, pelo perfil do grupo selecionado.
} 
Piccinini, C. L.

O projeto de extensão desenvolvido no Vale do Ribeira por dois anos e meio, tendo inicialmente por objetivo a "conscientização" da população ribeirinha quanto ao grave problema da verminose, que grassava absoluta na região, provocou não só a criação coletiva de atividades educativas para os moradores, como a aproximação e o diálogo mais estreito com estas pessoas. (MEMO 4)

Foi assim então que descobri uma das primeiras aplicações (e a mais difundida) da Educação Ambiental: auxiliar na conscientizaçãa ecológica das pessoas. (MEMO 5)

A fim de mais aproximar a comunidade da escola, a peça foi apresentada para o público local, inclusive com o objetivo de conscientizar a comunidade sobre a necessidade de acabar com vários lixões ali existentes. O trabalho deu ótimo resultado: os lixões desapareceram. (MEMO 10)

Ainda na formação inicial, encontramos o exemplo do memorial 12, no qual se destaca a fala de uma formadora de professores que, sendo entrevistada pelo educador ambiental, deixa-lhe uma "marca" a ponto de ser resgatada como parte de suas lembranças. Tais lembranças destacam a ideia de que, individualmente, é possível modificar a dualidade humano-natureza. Ela falou sobre a importância de se preservar o meio ambiente. Houve um verdadeiro encantamento de minha parte pela professora XXX, que até então eu não conhecia, e, mais do que isso, foi quando tive o despertar para a conscientização da necessidade de realizar ações para a preservação do meio ambiente. Muito mais do que uma simples entrevista, recebi uma verdadeira aula sobre educação ambiental. Além disso, ainda pude comprovar na essência o que é a verdadeira paixão por um ideal, por um acreditar que algo pode ser feito. Foi aí que tive a certeza de que podemos transformar situações, por mais adversas que sejam...

Não posso deixar de citar uma frase da professora que foi muito importante e que carrego comigo com muito carinbo: "A conscientização vai salvar o planeta, por uma reação em cadeia dos agentes multiplicadores da ecologia". (MEMO 22)

Sem pretender generalizar, aponto que os quatro enunciados citados podem remeter a um discurso que tem capacidade de anular ou consumir parte do potencial crítico da EA, porque encerram a visão de que o sujeito consciente pode mudar a sociedade ou colaborar para que outros, assim como ele, se tornem conscientes e transformadores desta sociedade, excluindo ou secundarizando a responsabilidade de outros segmentos, por exemplo: "sem explicitar o diferente peso dos atores sociais (Estado, mercado, sociedade, comunidade, indivíduo) na conformação deste quadro" (NOVICKI, 2007, p. 140). Ora, parece-me que esta lógica está invertida, visto que: “[...] O modo de produção da vida material condiciona o processo geral de vida social, político e espiritual. Não é a consciência dos homens que determina o seu ser, mas, ao contrário, é o seu ser social que determina sua consciência" (MARX, 1978, p. 129).

A visão apontada pode ajudar a manter uma característica antropocêntrica da relação humano-natureza, baseada na lógica: os homens que destruíram o planeta podem, agora, sal- 
vá-lo! Por conseguinte, seguindo esta linha equivocada de raciocínio, é preciso pensar no 'como' dar conta de tarefa tão grandiosa. Tal equívoco se contrapõe ao sentido dialético que entende que a "luta" entre humano e natureza não é fruto de um pensamento idealista e abstrato, mas resultado de um modelo de produção que se utiliza do humano-natureza para gerar lucro. Suponho, então, haver relação entre a busca empreendida pelos sujeitos desta pesquisa por ampliação da sua formação e a tarefa de resolver os impasses da complexa questão socioambiental. Retornamos, pois, ao início. É no falso deslocamento do histórico e social para o pensamento, o conhecimento e a consciência que residirão as transformações socioambientais.

Se, por um lado, a formação e o trabalho lhes garantem a possibilidade para o desenvolvimento de ações educativas, por outro, parecem suprimir os limites da educação, de seu alcance. Em ações educativas que tradicionalmente se limitam ao pontual e ao ocasional (no MEMO 10, este é um ponto que chama a atenção), parece ser difícil considerarmos a possibilidade de "conscientização ou de tomada de consciência" para que se alcance o propósito central da EA de transformação da realidade socioambiental. Além do mais,

Não parece ser possível transformar a relação humano-natureza sem transformar simultaneamente as relações sociais, porque as dinâmicas entre as esferas social e natural estão articuladas na mesma estrutura societária. Parece não bastar o estímulo à mudança cultural da visão de mundo fragmentada e reducionista, em direção à visão complexa, se o educando não for capaz de se desalienar de suas condições sociais [...]. (LAYRARGUES, 2004, p. 17)

Compreendo que a alienação tem sua origem nas relações de dominação e nas contradições decorrentes das relações de produção a que também estão submetidos os educadores ambientais.

A dimensão humana para realizar-se (ser emancipado) precisa ultrapassar a desigualdade de classes, a fragmentação científica, as relações de dominação, a hierarquia entre saberes e a exclusão social, em que a crítica e a capacidade de reflexão e superação atinjam o ser concreto e a sociedade na qual este se manifesta e se realiza. (LOUREIRO, 2004, p. 96)

Afinal, não se pode isolar o ato educativo do sistema e das formas de consciência que dominam a economia e as relações sociais. Nem tampouco nos limitarmos ao processo de construção de consciências críticas, capazes de uma leitura concreta e processual da realidade, visto que o objetivo não é somente a compreensão, mas a efetiva transformação do mundo (MARX; ENGELS, 2007).

Em oposição à visão simplificadora de uma consciência transportada de um sujeito para o outro, de uma consciência pronta e acabada, sobrepõe-se a visão de consciência no 
Piccinini, C. L.

movimento histórico ${ }^{5}$. Segundo Marx e Engels (2007, p. 35), "os homens desenvolvem a consciência no interior do desenvolvimento histórico real". Esta visão pode ser encontrada em duas narrativas distintas:

[...] Da análise que faço de todo esse percurso de formação e atuação como educadora, concluo que a minha experiência com a educação formal sempre foi algo muito importante para o meu desenvolvimento profissional. Mas, foi no Musen XXX que descobri, que pude perceber de forma mais ampla a importancia da cultura material para a promoção da consciência histórica, tão importante para a construção da cidadania. (MEMO 6)

A autora, ao procurar concluir a narrativa de seu memorial, relaciona consciência histórica com a construção da cidadania. Dessa forma, sua visão deixa de ser unidirecional e assume um foco coletivo e histórico.

\begin{abstract}
Antônio Joaquim Severino, no livro "Educação, Sujeito e História" considera a educação "como um processo intrinsecamente público, pois é sua tarefa inserir, a partir de mecanismos formais ou informais, o indivíduo em sen grupo cultural e em sua polis, de modo a torna-lo um socícola [...] sendo necessários mecanismos de aprendizagem, o que pressupõe referências significativas de sensibilização para que o indivíduo compartilhe vivências com seus semelhantes. [...] Também se identifica como processo de conhecimento e exercício de tomada de consciência individual e coletiva despertando as pessoas para sua condição de sujeito histórico. [...] Amplamente, e para efeito de incursão deste memorial, definimos educação ambiental como a otimização, sócio-bistoricamente construída, da compreensão nal da relação homem/mulher \& ambiente - físico, biótico e antrópico - como parte de um todo, cuja consciêntizacão bumana sobre o trabalbo, a sociabilidade e a cultura devam incluir reflexões teórico-práticas e ações pró-ativas para sua harmonia e sustentabilidade. (MEMO 12)
\end{abstract}

Neste memorial, percebemos o uso da paráfrase para apresentar a visão de educação, incluindo a ideia de consciência na perspectiva individual e coletiva no processo histórico.

\footnotetext{
5 “Na produção social da própria vida, os homens contraem relações determinadas, necessárias e independentes de sua vontade, relações de produção estas que correspondem a uma etapa determinada de desenvolvimento das suas forças produtivas materiais. A totalidade destas relações de produção forma a estrutura econômica da sociedade, a base real sobre a qual se levanta uma superestrutura jurídica e política, e à qual correspondem formas sociais determinadas de consciência. $\mathbf{O}$ modo de produção da vida material condiciona o processo geral de vida social, político e espiritual. Não é a consciência dos homens que determina o seu ser, mas, ao contrário, é o seu ser social que determina sua consciência. Em uma certa etapa de seu desenvolvimento, as forças produtivas materiais da sociedade entram em contradição com as relações de produção existentes ou, o que nada mais é do que a sua expressão jurídica, com as relações de propriedade dentro das quais aquelas até então se tinham movido [...]" (MARX, Prefácio Para a Crítica da Economia Política, 1978, p. 129-130, grifos da autora).
} 
Em seguida, conceitua educação ambiental, separadamente. Inclui a ideia de trabalho, sociabilidade e cultura tanto na perspectiva teórica, quanto na prática. Parece que tal abordagem concorre para uma visão menos reducionista ao incluir tanto os aspectos biológicos quanto sociais e históricos, ao relacionar teoria-prática-ação.

Nos memoriais também aparecem registros sobre um movimento de autoconhecimento, de autocrítica vinda da experiência com o outro e com a natureza:

Ninguém melhor que Paulo Freire para falar sobre a consciência do inacabamento. A formação ética que o fazía relacionar-se com o outro como sujeito e não como objeto permitia-lhe manter-se sempre aprendendo e ensinando. Os ensinamentos de Paulo Freire têm marcado profundamente a minha formação continuada. Eles estão presentes no dia-a-dia de minha prática pedagógica desde início no Colégio XXXX. (MEMO 6)

Na medida que o tempo passava, ou quanto mais andava pelas matas e rios, mais tomava consciência que sabia muito menos que qualquer criança da região sobre regras básicas de sobrevivência, ou sobre a aventura (imaginada ou não) que, só depois, percebi ter vivido. (MEMO 19)

Aprendi a amar a natureza e a construir a consciência de que sou membro de uma das espécies que vivem sob a terra... me sentir, eu mesma, enquanto natureza... dos pontos de vista físico, espiritual e intelectual. (MEMO 20)

Ao nos tornarmos "homens coletivos", ao repensarmos nossa própria concepção de mundo, iniciamos a elaboração crítica e tomamos consciência daquilo que somos - "conhecete a ti mesmo como produto do processo histórico até hoje desenvolvido, que deixou em ti uma infinidade de traços acolhidos sem análise crítica" (GRAMSCI, 2004, p. 94). Este movimento de autoconhecimento novamente apontou a visão de uma consciência que se reconhece como em processo de reflexão e superação dos limites impostos pela alienação. Tal superação, apesar de indicar níveis distintos a cada sujeito, favorece uma visão crítica do estar no mundo, do estar no mundo com o outro e da relação humano-natureza.

Ponto de destaque nos enunciados é o fato de as ações envolverem outros sujeitos do processo educativo que, muitas vezes, se encontram em um universo distante daquele ocupado pelos educadores ambientais. Esse distanciamento aparece nos memoriais capitaneados pela necessidade de "aproximação e diálogo", imerso na diferenciação existente entre a realidade, o "modo de pensar popular" (GRAMSCI, 2004, p. 94) e o modo acadêmico ou escolar, mais familiar aos educadores. Registra-se uma preocupação com o processo comunicativo, conforme indicado no primeiro exemplo, e a ampliação do olhar sobre os envolvidos e a(s) questão(ões) socioambiental(ais) que beneficiaram tanto aos extensionistas como às populações.

O projeto de extensão desenvolvido no Vale do Ribeira por dois anos e meio, tendo inicialmente por objetivo a "conscientização" da população ribeirinha quanto ao grave problema da verminose, que grassava absoluta na região, provocou não só a criação coletiva de atividades educativas para os moradores, como a aproximação e 
Piccinini, C. L.

o diálogo mais estreito com estas pessoas. Descobrimos assim, outro problema bastante sério do ponto de vista biológico e social - a ameaça da aprovação de sete barragens no rio Ribeira do Iguape. A região era conhecida por seu tesouro espeleológico ainda pouco explorado, por ser o último remanescente contínuo de mata atlântica do estado e por ser verdadeiro berçário da América Latina para incontáveis espécies. Com as barragens, cavernas, estuário e matas desapareceriam. Mas nosso olhar se ampliara e percebemos (o grupo de extensão) que os quilombolas também corriam riscos: entre eles, o crescimento acelerado da cidade com aumento da violência, do alcoolismo e da prostituição, devido à chegada de grandes levas de operários para as obras. A cidade não comportava o inchaço abrupto que se processaria e sequer seria beneficiada pela energia elétrica gerada. (MEMO 4)

No segundo exemplo, fica demonstrada a necessidade de redirecionar o projeto de $\mathrm{EA}$, que não consegue sensibilizar os adultos, mas faz uma aproximação com as crianças na medida em que, segundo a autora, estabelece nexo com seus cotidianos, com suas realidades.

Foi assim então que descobri uma das primeiras aplicações (e a mais difundida) da Educação Ambiental: auxiliar na conscientização ecológica das pessoas. $O$ primeiro obstáculo que encontrei para a realização deste trabalho foi a aceitação de nossa presença pela comunidade.

Como "representantes" da Universidade, éramos vistos como uma espécie de ameaça à permanência deles naquele local, [...]. Tentamos, de várias maneiras, nos aproximar dos moradores, mostrando que nosso objetivo não era prejudicá-los, e sim ajudá-los a ter uma melhor qualidade de vida.

Através desse processo, parcialmente infrutifero, descobri as crianças e jovens como meio de concretização do trabalho de Educação Ambiental. Daípara frente foi só envolvimento e dedicação integrais. As escolas que atendiam a comunidade da $V$ ila dos Funcionários eram carentes de projetos como o nosso, que pretendia levar àquelas crianças outras atividades e abordagens. Diferentes das comumente utilizadas no ambiente escolar e voltadas para o seu cotidiano, para a sua realidade, o retorno não poderia ter sido mais recompensador. (MEMO 5)

Seguindo a linha analítica, questiono se os trabalhos realizados em equipe, especialmente os de extensão universitária (MEMOS 4 e 5), resultaram no desenvolvimento de uma "consciência coletiva" ou se este constitui mais um não-dito dos memoriais. Contradição importante de se problematizar, visto que, no próprio grupo, seria mais fácil aproximarem-se de algum tipo de consciência coletiva.

\footnotetext{
${ }^{6}$ No Caderno 11, Gramsci (2004) vai discutir os métodos para a elaboração da cultura e da consciência. Para o autor, o modo de pensar não é inato, mas está articulado a sua aquisição - 'especialização' -, e as mudanças não acontecem através de 'explosões' rápidas ou de generalizações decorrentes, mas são parte de um todo, de processo lento e cumulativo de pensamento, de crítica e de persuasão. Em vários pontos de sua obra, o autor vai indicar a necessidade de "elaboração unitária de uma consciência coletiva" (GRAMSCI, 2004, p. 94).
} 
Para resumirmos brevemente esta discussão, é importante destacar a possibilidade do ato educativo, lembrado por Loureiro, de ultrapassar o plano das ideias e da transmissão de informações e agir no plano da existência, onde

O processo de conscientização se caracteriza pela ação com conhecimento, pela capacidade de fazermos opções, por se ter compromisso com o outro e com a vida. Educar é negar o senso comum de que temos "uma minoria consciente", secundarizando o outro, sua história, cultura e consciência [...]. Ninguém modifica a consciência separada do mundo [...]. (LOUREIRO, 2004, p. 28)

\section{Considerações}

É preciso reconhecer que só educação quer tenha ela o adjetivo "ambiental" ou não, não será suficiente para dar conta dos complexos problemas que nos desafiam neste final de século. Reconhecer os limites da educação é uma necessidade que se relaciona, entre outras coisas, com o fato de haver hoje, mais do que nunca, uma tendência em se dividir desigualmente os problemas "ambientais" e que embora uma mudança nas idéias possa gerar uma mudança nas condições materiais, só o mundo das idéias é insuficiente para concretizar determinadas mudanças materiais. Paula Brügger (2004, p. 179)

A ideologia dominante tem conformado a consciência da classe trabalhadora (MARX; ENGELS, 2007), e aqui não se excluem os educadores ambientais, grupo que, pela sua origem e organização inicial, deveria contestar a sociedade capitalista e os seus desdobramentos deletérios à vida planetária (LOUREIRO, 2004). Conforme verificado, manifesta-se, em algumas trajetórias, um discurso ingênuo e acrítico sobre consciência ambiental que, supostamente, deveria estar fundada em uma consciência crítica.

O "discurso sobre a consciência" não surge como consciência de classe, mas como consciência ingênua, mesclada ao desejo de poder contribuir para as mudanças das contradições socioambientais do capitalismo, mas sem assumir um papel de confronto à ideologia dominante. Pensa-se ser possível transitar de uma consciência individualista, centrada no sujeito e ingênua, no sentido de que o indivíduo transforma a sociedade, para um movimento de construção coletiva da consciência e, mais especificamente, da consciência ambiental.

Mais adiante, em algumas memórias, a visão de EA está vinculada com a preocupação de se conscientizarem os educandos para a necessidade de um outro entendimento da relação homem-natureza. Mas esta "preocupação" permanece alienada da práxis de alguns indivíduos. São experiências que se conectam às memórias da infância, da família, da escola/ professores e de desejos preservacionistas, que mais parecem se estabelecer como um ideal voluntarista ou, ainda, como anuncia Kosik (1976, p. 69), em seu livro A dialética do concreto, como uma "expressão de sua preocupação". 
A intenção de poder mudar o próprio rumo e o mundo mediante o conhecimento e a educação se relaciona à ideia de busca de um ideal que se consolida por meio da construção de uma tradição ideológica (GRAMSCI, 2004), muito presente entre os educadores ambientais (CARVALHO, 2002; GUIMARÃES, 2004); e que, neste ponto do diálogo, reflete, por intermédio dos argumentos apresentados, a busca de um objetivo comum, onde a educação se apresenta como um recurso necessário para a melhoria da sociedade e para a superação da crise socioambiental.

Porém, se esta perspectiva acentua o papel do profissional educador, por outro lado, reflete o que Sacristán (1999) menciona como "ocultação ideológica", de caráter consciente ou não, das reais condições dessa prática, e que redunda na "hiper-responsabilização" (SACRISTÁN, 1999) atribuída aos docentes pela sociedade e, algumas vezes, introjetada e assumida como verdade pelos mesmos.

"Há um idealismo que se manterá presente nas vozes destes educadores e que limitam suas narrativas quando conectadas à realidade" (PICCININI, 2009, p. 203). Em alguns casos, esta visão será transposta para outra dimensão, com a realização de ações que buscam a transformação concreta da sociedade, estabelecendo-se em práxis e em novos nexos em relação às representações de homem-natureza.

A realidade multifacetada da EA demonstra a necessidade de articulação do trabalho entre distintas áreas do conhecimento, tanto para a compreensão quanto para as interferências que se destinem à transformação da realidade socioambiental; exige domínio e articulação de estratégias de investigação e de informação; exige a inserção em espaços sociais diversos e a compreensão do mundo/linguagem do outro; pressupõe a horizontalidade de saberes; a capacidade de somar e articular diferenças no trabalho coletivo; enfim, evitando reducionismos, mas considerando as diferentes dimensões sócio-históricas, biológicas, culturais, econômicas e políticas, que lhe vão permitir realizar ações que transcendam a dicotomia homem-natureza (alienação).

É central supor que, ao pensarmos sobre a formação da nova geração de educadores ambientais, tenhamos em mente a noção do papel que esses educadores, vistos como intelectuais, podem ter para compreenderem criticamente as barreiras que impedem a EA de se consolidar como uma esfera contra-hegemônica.

Seria necessário que os espaços de formação assumissem verdadeiramente a lógica de contestação da EA, isto é, de crítica ao modelo socioambiental, de conexão com as lutas dos subalternos, de construção de conhecimentos e práticas contra-hegemônicas, que apostassem no trabalho coletivo e cooperativo (VASCONCELLOS, 2008). Seria necessário que, nos espaços de trabalho, os educadores ambientais também lutassem não só para a resolução dos conflitos socioambientais, mas também para a elevação da sua consciência histórica e do grupo ao qual pertencem (GRAMSCI, 2004). 
O discurso sobre a consciência ...

\section{Referências}

AMORIM, M. A contribuição de Mikhail Bakhtin: a tripla articulação ética, estética e epistemológica. In: FREITAS, M. T.; JOBIM E SOUZA, S.; KRAMER, S. (Orgs.).

Ciências humanas e pesquisa: leituras de Mikhail Bakhtin. São Paulo: Cortez, 2003. p. 11-25.

BAKHTIN, M. Estética da criação verbal. 4. ed. São Paulo: Martins Fontes, 2003. Marxismo e filosofia da linguagem. 3. ed. São Paulo: Hucitec, 1986.

BRASIL. Ministério da Educação e do Desporto. Secretaria de Educação Fundamental. Parâmetros curriculares nacionais: meio ambiente e saúde. Brasília: SEF, 1997.

BRÜGGER, P. Educação ou adestramento ambiental? 3. ed. Florianópolis: Letras Contemporâneas, 2004.

CARVALHO, I. C. M. A invenção ecológica: narrativas e trajetórias da educação ambiental no Brasil. Porto Alegre: Ed. da UFRGS, 2002.

DIAS, G. F. Educação ambiental: princípios e práticas. 2. ed. São Paulo: Gaia, 1993.

DUTRA, M. R. O. Professores e a educação ambiental: uma relação produtiva. 2005. 136f. Dissertação (Mestrado em Educação) - Faculdade de Educação, Universidade Federal de Pelotas, Pelotas, 2005.

FREIRE, P. Educação e mudança. Rio de Janeiro: Paz e Terra, 1981.

GRAMSCI, A. Cadernos do cárcere. 3. ed. Rio de Janeiro: Civilização Brasileira, 2004. v. 2.

GUIMARÃES, M. A formação de educadores ambientais. Campinas: Papirus, 2004.

JACOBI, P. Educação ambiental, cidadania e sustentabilidade. Cadernos de Pesquisa, São Paulo, n. 118, p. 189-205, 2003.

JAPIASSU, H.; MARCONDES, D. Dicionário básico de filosofia. Rio de Janeiro: Jorge Zahar, 1991.

KOSIK, K. A dialética do concreto. Rio de Janeiro: Paz e Terra, 1976.

LAYRARGUES, P. P. Prefácio. In: GUIMARÃES, M. (Org.). A formação de educadores ambientais. Campinas: Papirus, 2004. p. 11-16.

LOUREIRO, C. F. Trajetória e fundamentos da educação ambiental. São Paulo: Cortez, 2004.

MARX, K. Prefácio para a crítica da economia política. In: __. Manuscritos econômicos e filosóficos e outros textos escolhidos. 2. ed. São Paulo: Abril Cultural, 1978. p. 127-132. (Coleção Os pensadores, 35).

MARX, K.; ENGELS, F. A ideologia alemã. São Paulo: Boitempo, 2007. 
Piccinini, C. L.

NOVICKI, V. Competências socioambientais: pesquisa, ensino e práxis. Boletim Técnico do SENAC, Rio de Janeiro, v. 33, n. 3, p. 18-34, 2007.

PICCININI, C. L. A formação e o trabalho dos educadores ambientais: um diálogo com as memórias. 2009. 269f. Tese (Doutorado em Educação) - Faculdade de Educação, Pontifícia Universidade Católica do Rio de Janeiro, Rio de Janeiro, 2009.

SACRISTÁN, J. G. Consciência e acção sobre a prática como libertação profissional dos professores. In: NÓVOA, A. (Org.). Profissão professor. Porto: Porto Editora, 1999. p. 63-92.

VASCONCELLOS, M. M. N. Educação ambiental na colaboração entre museus e escolas: limites, tensionamentos e possibilidades para a realização de um projeto político pedagógico emancipatório. 2008. 386f. Tese (Doutorado em Educação) - Faculdade de Educação, Universidade Federal Fluminense, Rio de Janeiro, 2008.

Artigo recebido em 08/07/2010. Aceito em 01/11/2010. 